\title{
THE DESIGN AND FABRICATION OF STEERING
}

\section{CONTROLLED HEADLIGHTS}

\author{
RAJU. T ${ }^{1}$, KISHORE KUMAR. ${ }^{2}$, JAWAHAR. $M^{3} \&$ JEEVAN REDDY. $\mathbf{C}^{4}$ \\ ${ }^{1,3,4}$ Jayamukhi Institute of Technological Sciences, Warangal, India \\ ${ }^{2}$ Kakatiya Institute of Technological Sciences, Warangal, India
}

\begin{abstract}
The main aim of any design should not only be focused on 'Customer satisfaction' but also 'Customer safety'. Following this, the number of accidents have been witnessed only due to ill lighting facilities provided in an automobile. Keeping this drawback in view "Steering Controlled Headlight System" has been proposed which would hopefully turn out to be a boon to the people driving through the curved roads during night times.

Automobiles are controlled by steering system. The steering system helps the driver to guide the moving vehicles on the road by turning it right or left according to his wishes. Hence a combination of this steering mechanism with a gear mesh mounted on a cam plate with a link mechanism tilts the headlights in the direction as per the rotation of the steering. This mechanism has been incorporated in BMW, Audi Q-7 and Benz, etc., to ensure a safer drive.

KEYWORDS: Customer Satisfaction, Customer Safety, Curved Roads, Cam Plate Link Mechanism BMW, AudiQ-7, Benz \& Safer Drive
\end{abstract}

Received: May 21, 2019; Accepted: Jun 01, 2019; Published: Jun 29, 2019; Paper Id.: IJMPERDAUG201940

\section{INTRODUCTION}

The steering system helps the driver to guide the moving vehicle on the road and turns the vehicle right or left according to his wishes. Safety of many automobiles is mainly dependent upon the performance of the steering and braking systems. Automobiles are controlled by steering system. Directional changes are provided by this steering system to the moving automobiles.

In this system, the rotary motion of the steering wheel is converted into angular turning of the wheels. Steering is done by moving the axes of rotation of the front wheels with respect to the chassis frame.

\section{LITERATURE REVIEW}

J. P. Lowenau, J. H. Bernasch, H. G. Rieker, J. P. Huber, F. M. Riech developed a new light concept called "Adaptive Light Control (Alc)" which improves the headlamp illumination by means of continuous adaption of headlamps according to the current driving situations and environment.

T. Hacibekir, S. Karaman, E. Kural, E. S. Ozturk, M. Demirci presented a paper on "Adaptive Headlight System Using Hardware-In-The-Loop Simulation”. The Adaptive Headlight system is an active safety system, where the headlamps orientation control system rotates the right or left low beam headlights independently and keeps the beam as parallel to the curved road as possible to provide better night time visibility. 
Alex D. Hwang And Eli Peli of Schephens Eye Institute submitted a paper introducing a second generation of headlight glare simulator to be used with a driving simulator that significantly improves spatial and brightness accuracy of previously developed prototype headlight glare simulator.

Naresh Kamble and S. K. Saha developed a virtual prototype of a rack and pinion steering system. For a typical Rack and Pinion Steering gear used in light vehicles, span of movement of the rack is limited to approximately four rotations of the pinion. For this limited speed of rack travel, the torque required to rotate the pinion is tested for satisfactory functioning of the steering gear.

T. Kobayashi And H. Shibata presented a paper on 'Estimation of Rack Swing Torque for Rack and Pinion Steering Gear' considering friction during rack and pinion gear meshing without backlash and estimate rack swing torque based on consideration of rack and pinion gear meshing normal force, frictional force between two surfaces, spring force from the rack guide, etc.

Rajiv Dey submitted issued a paper on 'Electronic Power Assisted Steering System' which offers greater vehicle safety by adapting variable steering ratio to human needs, filtering drive train influences and even adjusting active steering torque in critical situations.

\section{STUDY ON STEERING MECHANISM}

\section{Introduction- Steering}

The control of a vehicle is done by means of steering system which provides directional changes to the moving vehicle. The steering system converts rotary movement of the steering wheel into angular turn of the front wheels and also multiplies the driver's effort with leverage or mechanical advantage for turning easily.

There are two types of steering mechanism.

- Davis steering gear mechanism.

- Ackermann steering gear mechanism.

Ackermann steering mechanism is preferred to the Davis steering gear mechanism because of its simplicity.

\section{Ackermann Steering Gear Mechanism}

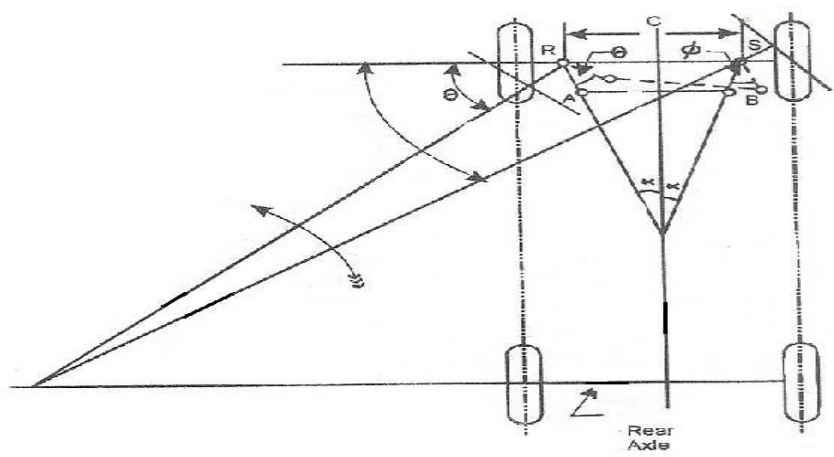

Figure 1: Ackermann Steering Gear Mechanism

The Ackermann steering gear mechanism is very much simpler than Davis steering gear. The Ackermann steering gear consists of turning pairs and the whole mechanism is on the back of the front wheels. ABCD is a four bar crank chain. 
The links BC and AD are connected with each other through track rod "CD" When the vehicle is in straight these links make equal angles with centre line of the car.

The following are the three positions for correct steering.

- When the vehicle moves along a straight path, the longer links AB and CD are parallel. Shorter links BC and CD are equally inclined to the axis.

- When the vehicle is steering to the left, the lines of the front axle intersect on the real axle at instantaneous centre.

- When the vehicle is steering to the right, the similar intersection may be obtained.

\section{Steering Linkages}

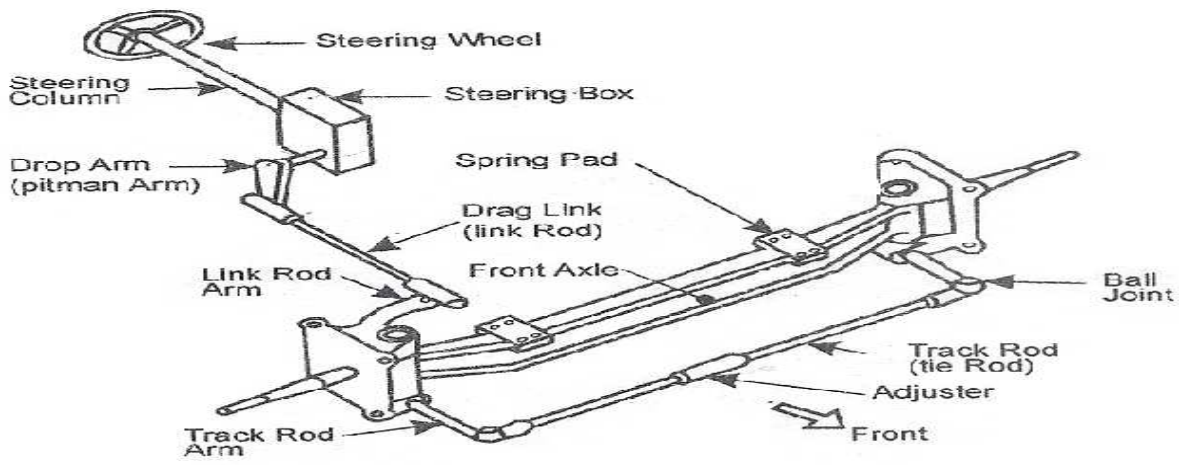

Figure 2: Steering Linkage for Rigid Axle Suspension

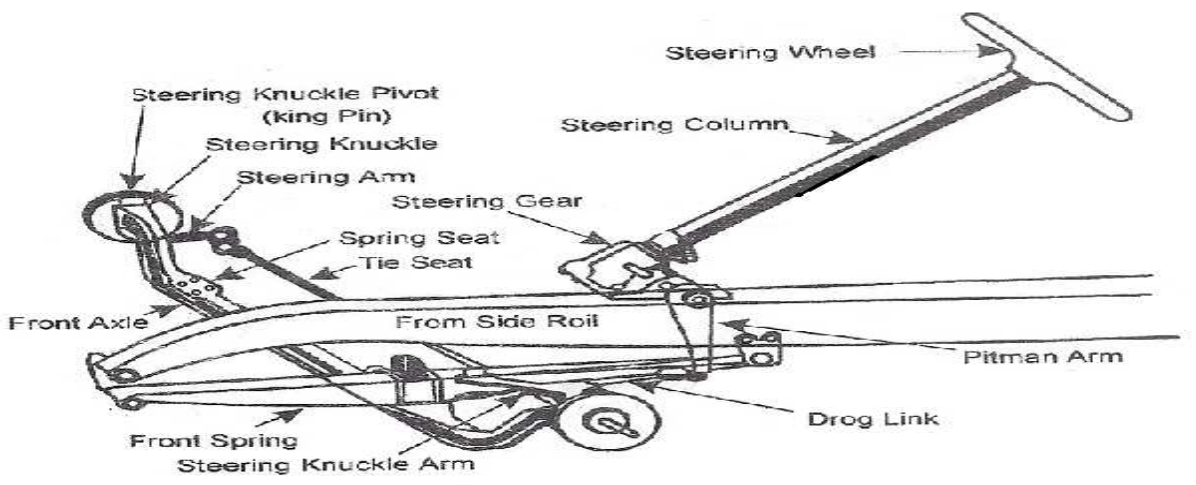

Figure 3: Conventional Steering Mechanism

When the steering wheel is turned steering column also turns and is connected to the steering shaft in the steering gear box. The steering gearbox converts the steering wheel into linear motion of the steering linkages and also multiplies the effort applied by the driver. The pitman arm also called as drop arm converts the output torque from the steering gear box into force to the drag link. The ball joints take care of the angular displacement and rotational movement. The drag link is connected to the (either left or right) steering knuckle. It converts the drag link force into the turning moment about king pin and the wheel is steered. Simultaneously the other wheel is also steered by meaning of track rod (tie rod).

\section{Steering Geometry}

Steering geometry is the mechanics of adjusting or setting of the front wheels and the steering mechanism for obtaining the free rolling movement of the wheels on the road. The important alignment factors are as under. 
- Camber

- Caster

- $\quad$ King pin inclination

- Included angle

- Toe-in \& toe-out

\section{- Camber}

Front wheels are not mounted parallel to each other. They are tilted outward slightly at the top and inward at the bottom. The angle between the centre line of the tyre and the vertical line when viewed from the front of the vehicle is known as camber. Camber provided may be positive or negative. When the wheel tilt is outward i. e., the distance between the top of the wheels is greater than the distance between the bottom, the chamber is positive. When the wheel tilt is inward i. e., the distance between the bottom of the wheels is greater than the distance between the top, the camber is negative.

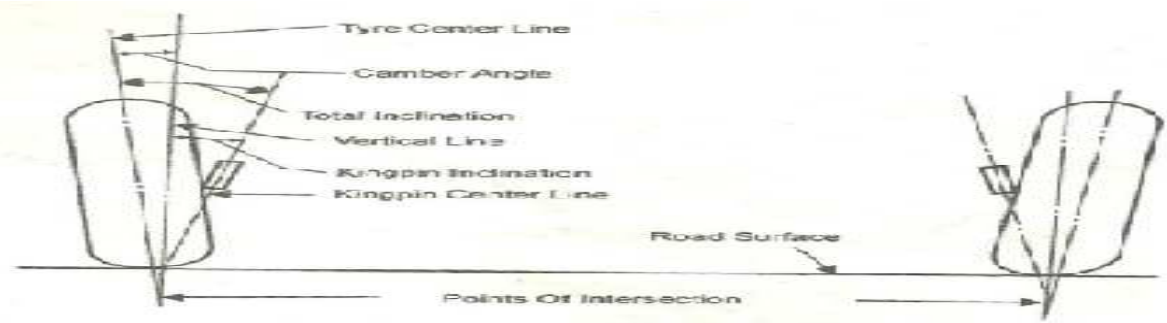

Figure 4: Camber Angle (Positive) and King Pin Inclination

The purpose camber is to prevent inward tilting too much caused due to excessive load or play in the king pins and wheel bearings. The camber on both the wheels must be equal. The amount of camber is generally in between $0^{0}$ to $1.5^{0}$.

\section{- Caster}

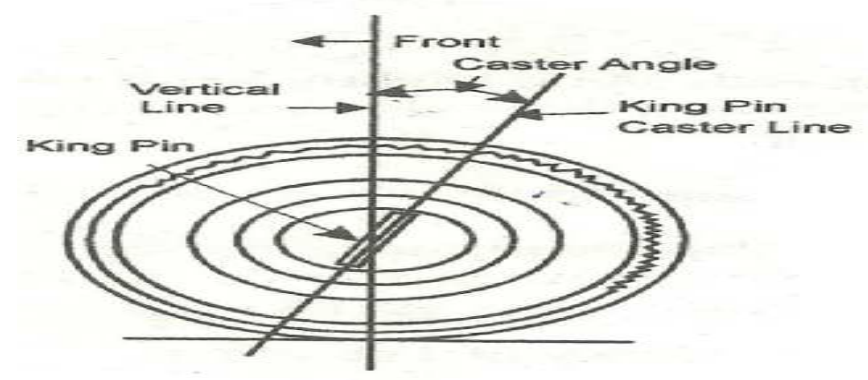

Figure 5: Caster Angle

The king pins are tilted slightly forward or backward from the vertical line. The angle between the vertical line and the king-pin line when viewed from the side of the wheel is known as caster angle. The caster angle may be positive or negative. When the top of the king-pin is backward, the caster angle is positive and if it is forward, the caster angle is negative. Caster produces directional stability and avoids the oscillation of the front wheels. The caster angle ranges from $2^{0}$ to $8^{0}$. 


\section{- King-Pin Inclination}

King pin and ball joints are mounted so that they inclined inward as shown in figure 6 . The angle between the vertical line and the king pin centre line when viewed from is known as king pin inclination or steering axis inclination. King pin inclination is used to provide directional stability and to bring back the wheels in a straight position after a turn. This angle is kept between $3^{0}$ and $9^{0}$.

\section{- Included Angle}

The sum of camber angle and king pin inclination is called included angle. Its value ranges from $5^{0}$ to $12^{0}$.

\section{- Toe-In \& Toe-Out}

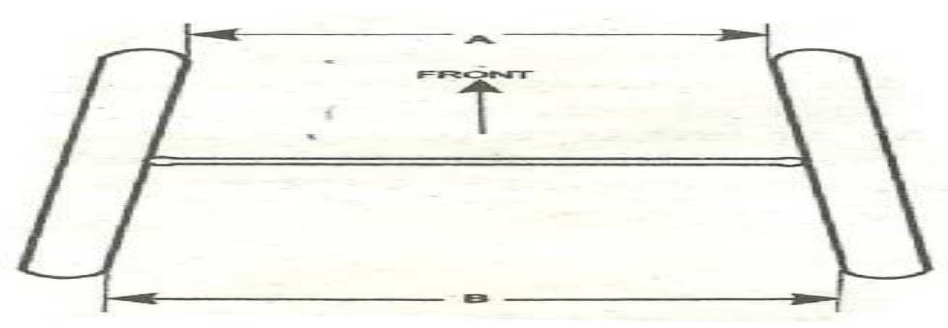

Figure 6: Toe in \& Toe out

The front wheels are set closer at front than the rear in stationary position when viewed from the top. The distance between the front ends (A) is slightly less than the distance between the back ends (B) of front wheel. The difference between these distances is called Toe-in (B-A). The amount of Toe-in is generally between 3 to $5 \mathrm{~mm}$. This is provided to stabilize steering and to prevent excessive tyre wear. The front wheels may be set, so that the distance between the front ends (A) is slightly greater than the distance between the back ends (B) when viewed from the top of a stationary vehicle. The difference between these distances is called Toe-out (A-B). This is provided to counter the tendency of Toe-in.

\section{Correct Steering Angle}

A perfect steering means all four wheels undergo only a rolling motion under all conditions whether the vehicle is going in straight, or left or right turn. This is possible only when the two stub axles of front wheel intersect at point 'O' as shown in figure. This point is called instantaneous centre. All the four wheels rotate about instantaneous centre.

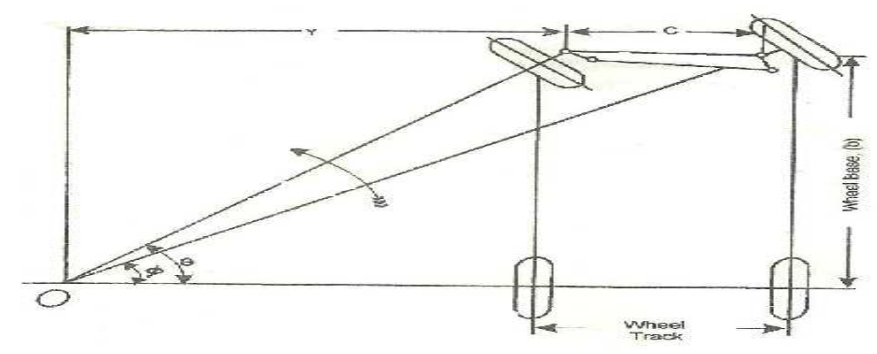

Figure 7: Correcting Steer Angle

For correct steering.

$\operatorname{Cot} \Phi-\cot \theta=c / b$

The values of $\Phi$ and $\theta$ differ for different vehicles depending on the dimensions of wheel base and wheel track. 


\section{Cornering Force}

When the vehicle takes a turn, the centrifugal force acts on the vehicle which produce side thrust. The angle through which the wheel has to turn to compensate the side thrust is called the slip angle. The force produced to resist the side thrust is called cornering force. This force acts at right angle to the plane of the wheel.

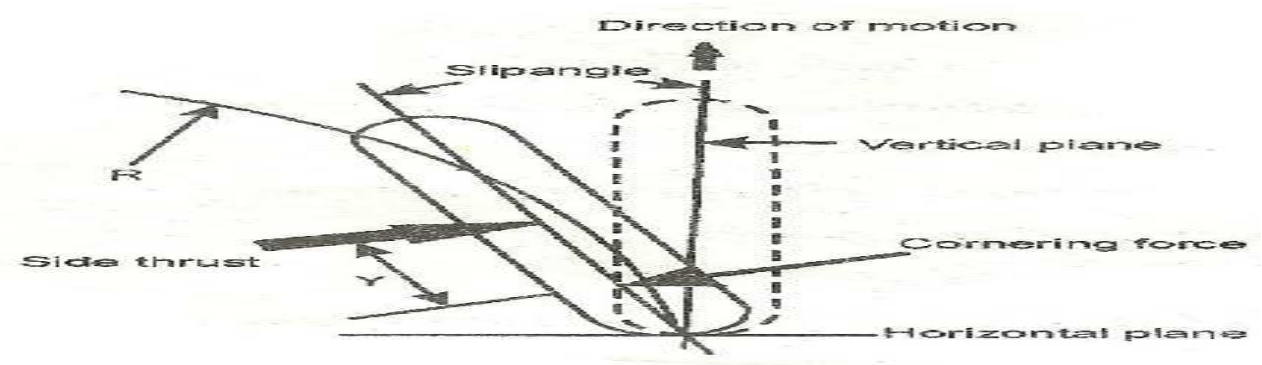

Figure 8: The Slip Angle and Cornering Forces

\section{MAJOR COMPONENTS OF STEERING CONTROLLED HEADLIGHTS SYSTEM}

The four major components of Steering controlled headlights are

- $\quad$ Rack and pinion steering

- Links

- Battery

- Headlights

\section{Positioning of Components}

The steering mechanism of an automobile consists of rack and pinion arrangement where the rotation of the steering is connected to the rack and pinion in turn connected to the front wheels by tie rods is responsible for the orientation of the wheels. On the extension of rack and pinion arrangement of steering mechanism a $\mathrm{Z}$ shaped bar is welded. The design of $\mathrm{Z}$ bar is based on the loads acting on it and so is its cross-section. To the end of the Z-bar another Cshaped bar is attached with two sides a provision to hold and transmit the headlights motion.

\section{Fixing of Headlights}

In order to achieve an orientation or movement of the headlight in a vertical plane the headlights must be fixed in such a way that it can orient about its vertical axis. Hence ball joints must be provided at the top and bottom of the headlights. In the front of the vehicle a casing must be provided to achieve the above requirements.

\section{Alternate Mechanisms at the Rear end of Headlights}

Three different possibilities of connecting the rear end of headlights to the Z-bar.

- $\quad$ Movable C-clamp

- Rack and pinion mechanism individually to both the headlights

- $\quad$ Springs 


\section{Movable C-Clamp}

The headlights are held horizontally by individual movable C-clamps. These C-clamps are held by a C-shaped bar at each end behind the headlight. As the Z-bar moves linearly, this motion is transmitted to the C-Clamps which orient the headlights in required direction.

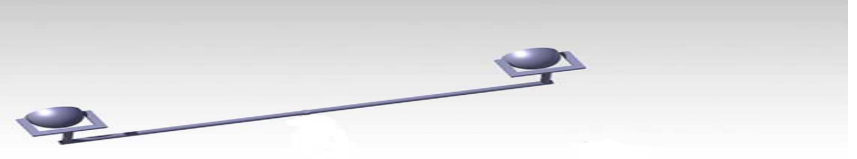

Figure 9: Movable C-Clamp

\section{Rack and Pinion Mechanism}

To fix the rotation or to obtain required orientation, rack and pinion combination can be installed at the rear end of each headlight. As the Z-bar transmits the motion to C-shaped bar which in turn transmits it to the rack and pinion which changes the linear motion to rotary motion of the headlights. Here the pinion is fixed to the headlights at the rear end.

\section{Springs}

Springs can be welded to the extension provided at the rear end of the headlights. Due to the linear motion of Cshaped bar the spring is extended and hence pulls the headlights to one side. As headlights are held vertically they orient in required direction.

\section{Comparison between Three Mechanisms}

- C-clamp design at the rear end of the headlights is acceptable but required rotation cannot be fixed.

- Rack and pinion design is a laborious process but provides precision and required orientation.

- The arrangement is easy but the springs on rotation of headlights pay to deflection hence not preferable.

The preferred mechanism in this design is movable C-Clamp.

\section{DESIGN AND DEVELOPEMENT OF STEERING CONTROLLED HEADLIGHTS}

Part List

This chapter describes the part details of Steering controlled headlights system. The major components designed are listed below.

- C-Clamp

- C shaped bar

- Z shaped bar

\section{Design of Parts}

"Design of each component varies from car to car." 
As the headlights are held within the casing using ball-joints, the weight of the headlights is neglected while finding the dimensions of the $\mathrm{C}$-clamp. C-clamp is divided in three sections I, ii, iii. The dimensions of ii, iii are equal and its length is equal to the rear end projection of headlight. The length of section $\mathrm{i}$ is equal to the diameter of the headlight. Thickness and breadth are assumed and the remaining parts are designed according to the dimensions of headlights.

\section{Volume of C-Clamp}

\section{Section I}

$\mathrm{l}=15 \mathrm{~cm}$ (diameter of headlight); $\mathrm{t}=0.5 \mathrm{~cm}$ (assumption); $\mathrm{b}=3 \mathrm{~cm}$ (assumption); $\mathrm{V}(\mathrm{i})=1 \times \mathrm{b} \times \mathrm{t}=22.5 \mathrm{~cm}^{3}$

\section{Section ii, iii}

$\mathrm{l}=12 \mathrm{~cm}$ (rear end projection); $\mathrm{t}=0.5 \mathrm{~cm} ; \mathrm{b}=3 \mathrm{~cm} ; \mathrm{V}(\mathrm{ii})=\mathrm{V}(\mathrm{iii})=\mathrm{l} \times \mathrm{b} \times \mathrm{t}=18 \mathrm{~cm}^{3}$

Total volume of C-clamp=V (i) $+\mathrm{V}($ ii $)+\mathrm{V}$ (iii) $;=22.5+18+18 ;=58.5 \mathrm{~cm}^{3}$.

\section{Weight of C-Clamp}

Considering the Material to be Cast Iron, Its Density Is $7.2 \mathrm{gm} / \mathrm{Cm}^{3}$

Density (D) =Mass (M)/Volume (V)

$\mathrm{m}=\mathrm{d} \times \mathrm{V} ;=7.2 \times 58.5$

$=421.2 \mathrm{gm}$

$\mathrm{W}=\mathrm{m} \times \mathrm{g}=421.2 \times 981$

$=4.13$ Newton

Weight of C-clamps acts on both the ends of $\mathrm{C}$ shaped bar connecting to headlights.

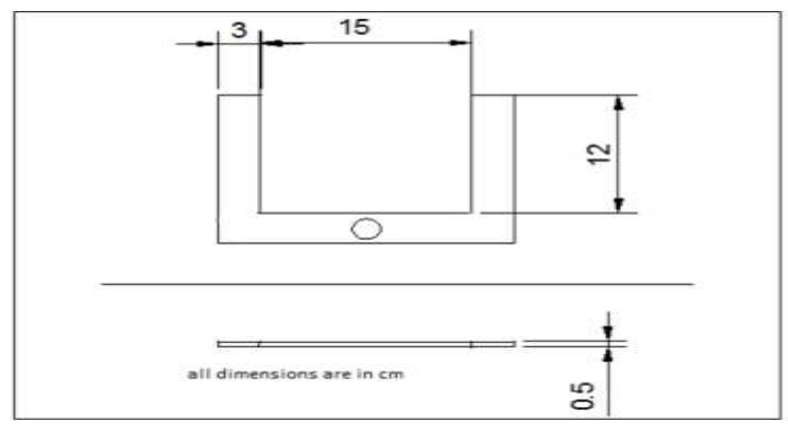

Figure 10: C-Clamp

\section{Design of C Shaped Bar}

The bar is supported at the centre by $\mathrm{Z}$ shaped circular bar. Length of the bar is equal to the distance between two centers of headlights i. e. $121 \mathrm{~cm}$. The cross sectional shape of the $\mathrm{C}$ shaped bar is assumed to be circular (square cross section can also be considered). The diameter of the $\mathrm{C}$ shaped bar is calculated by maximum bending stress criteria. Weight of the C-clamps acts on both the ends of the bar which was theoretically calculated to be 4.13 Newton.

The allowable bending stress is $40-50 \mathrm{Nmm}^{2}$ (assuming material to be cast iron)

$\sigma_{\mathrm{b}}=$ allowable bending stress. 
$\sigma_{b}=(32 \times M) /\left(\pi x^{3}\right)$

$\mathbf{M}=$ bending moment $=$ force $\mathbf{x}$ perpendicular displacement

$\mathrm{M}=4.13 \times(1210 / 2)$.

(Perpendicular distance of the force acting away from the midpoint i. e the point of consideration which is equal to $605 \mathrm{~mm})$

$$
\begin{aligned}
& =2498.65 \mathrm{Nmm} . \\
& \mathrm{d}^{3}=(32 \times M) /\left(\pi \times \sigma_{\mathrm{b}}\right) ; \mathrm{d}=((32 \times 2498.65) /(3.14 \times 40))^{1 / 3} \\
& \left(\text { assuming } \sigma_{\mathrm{b}}=40 \mathrm{Nmm}^{2}\right) ; \mathrm{d}=8.6 \sim 10 \mathrm{~mm}=1 \mathrm{~cm} .
\end{aligned}
$$

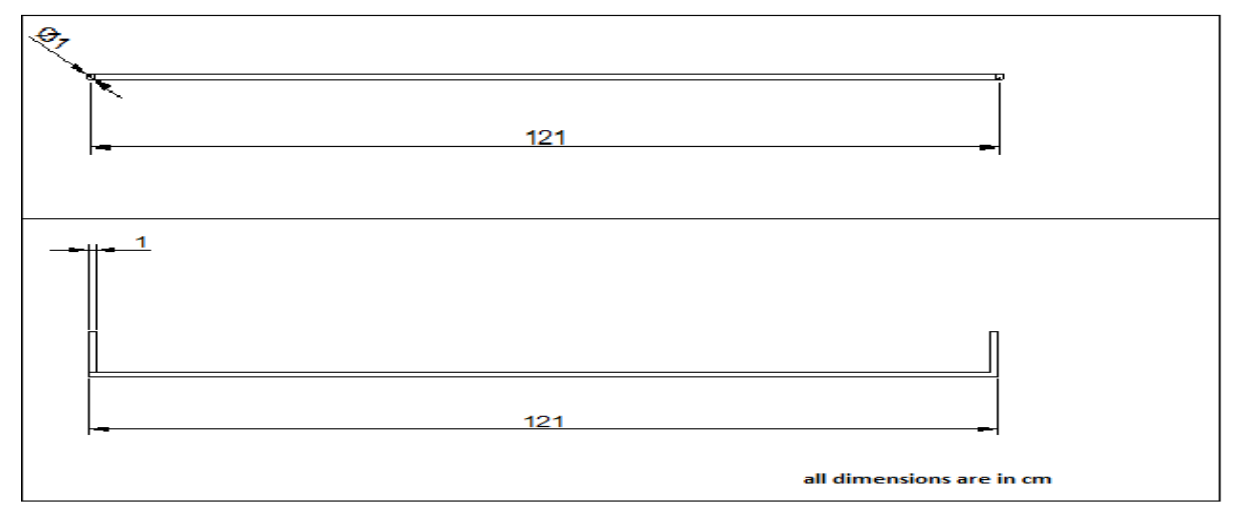

Figure 11: C Shaped Bar

\section{Design of Z Shaped Bar}

The length and height of the $\mathrm{Z}$ bar depends on size and shape of dome. The length of $\mathrm{Z}$ bar is equal to the parallel distance between the midpoint of connecting line of headlights and rack and pinion of the steering mechanism. The forces acting on $\mathrm{Z}$ shaped bar are weight of $\mathrm{C}$ shaped bar with clamps on both the ends and force acting normal to the axis of $\mathrm{Z}$ shaped bar at the bottom. The shape and dimensions of the $\mathrm{Z}$ bar are not universally accepted since it depends on the shape and size of the dome which eventually vary from car to car. The diameter is same as that of $\mathrm{C}$ shaped bar. The length of $\mathrm{Z}$ shaped bar is $89 \mathrm{~cm}$ (assuming the car to be TATA Indica and $\mathrm{Z}$ bar the material to be cast iron).

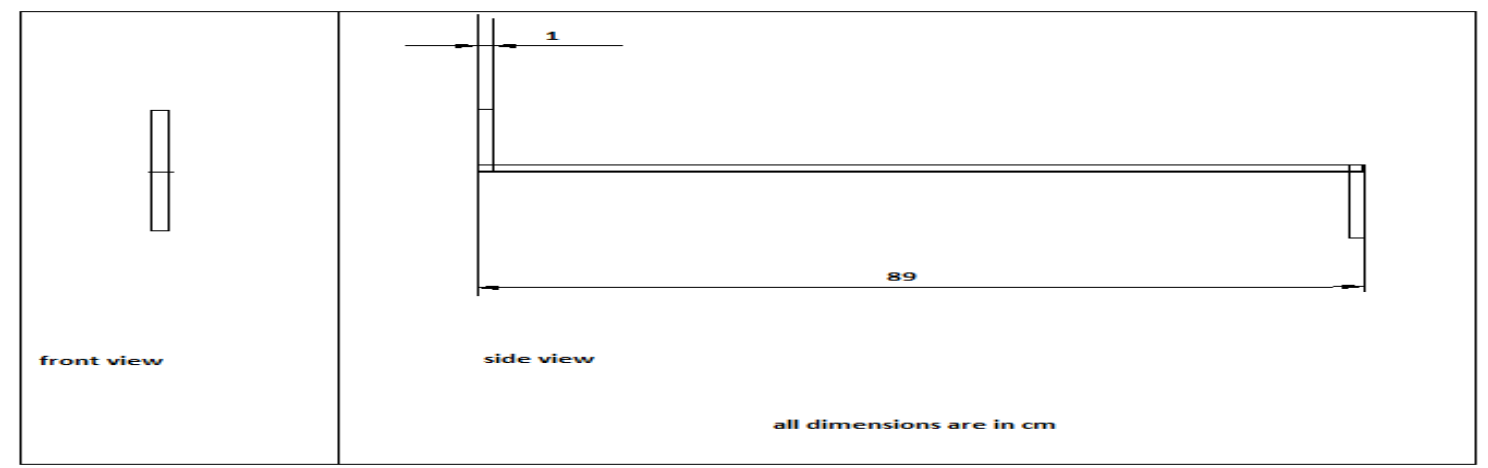

Figure 12: Z Shaped Bar 


\section{Assembled Figure (Catia Model)}

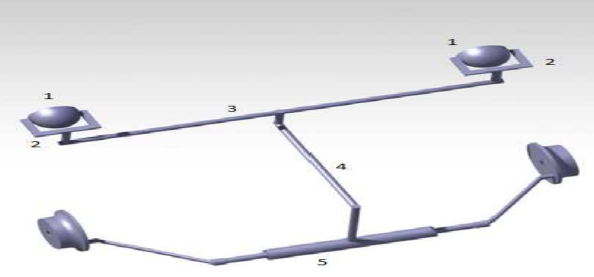

Figure 13: Assembled Model

- Headlights

- C-Clamp

- C shaped bar

- Z shaped bars

- $\quad$ Rack and pinion steering system

\section{Part List}

The parts of steering controlled headlights are listed below in the table given below.

Table 1

\begin{tabular}{|c|l|l|c|}
\hline S No & Part Name & Material & Quantity \\
\hline 1 & Z Shaped Bar & Cast Iron & 1 \\
\hline 2 & C Shaped Bar & Cast Iron & 1 \\
\hline 3 & C Clamp & Cast Iron & 2 \\
\hline 4 & Head Light & Acrylic & 2 \\
\hline
\end{tabular}

\section{Maximum Angle of Rotation of Headlight}

Here $\mathrm{BC}=$ displacement of rack on rotating the steering $=10 \mathrm{~cm}$.

$\mathrm{AB}=13.5 \mathrm{~cm} ;$ Tan $\varnothing=\mathrm{BC} / \mathrm{AB} ;=13.5 / 10 ; \emptyset=\mathbf{5 4}{ }^{\circ}$

Hence the maximum angle that headlight rotates on steering is $(90-\emptyset)=36^{\circ}$

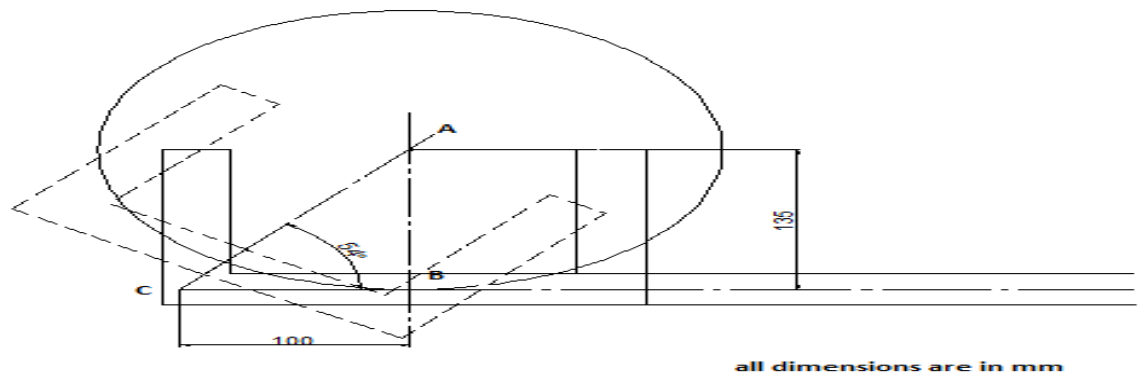

Figure 14: Maximum Angle of Rotation 


\section{FABRICATION OF STEERING CONTROLLED HEADLIGHTS (PROTOTYPE)}

\section{Description of the Model}

A carpentry model of Steering controlled headlights is designed and fabricated. It consists of two headlights fixed into a wooden plank which represents the casing to be provided in the cars dome. The headlights are held by ball joints along vertical axis and welded along horizontal axis to the movable C-clamp. These clamps are free to slide over the $\mathrm{C}$ shaped bar which is in turn held firmly by $\mathrm{Z}$ shaped bar.

\section{Working}

In an automobile when steering wheel is rotated, due to the rack and pinion mechanism connected to it, the rotation of the steering is converted to linear motion of the rack. At each end of the arrangement, tie rods are provided which pulls one wheel and pushes the other in required direction.

To the extension of the rack one end of the Z-bar is welded and the other end holds both the headlights with the help of a C-shaped bar. The headlights are held by movable C-Clamp (slide upon the ends of C-shaped bar). They are made to vertically rotate on their own axis by providing ball joints at the top and bottom ends. The linear motion of the rack is transmitted to the headlights through the links which converts it into the rotation of headlights.

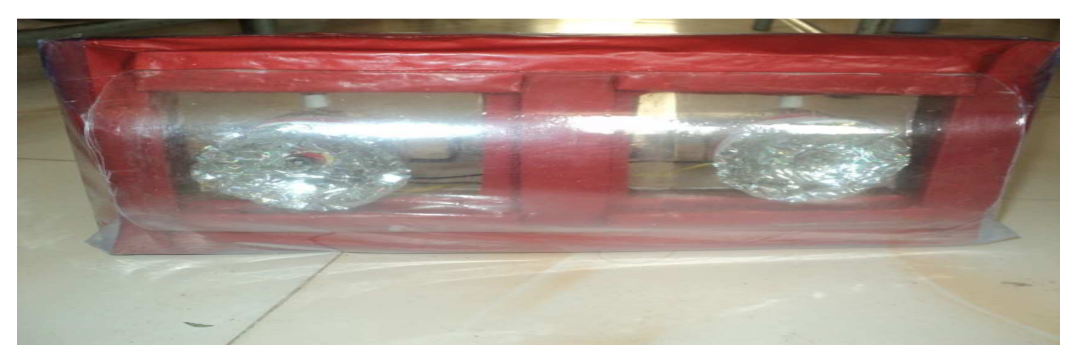

Figure 15: Fabricated Model (Front View)

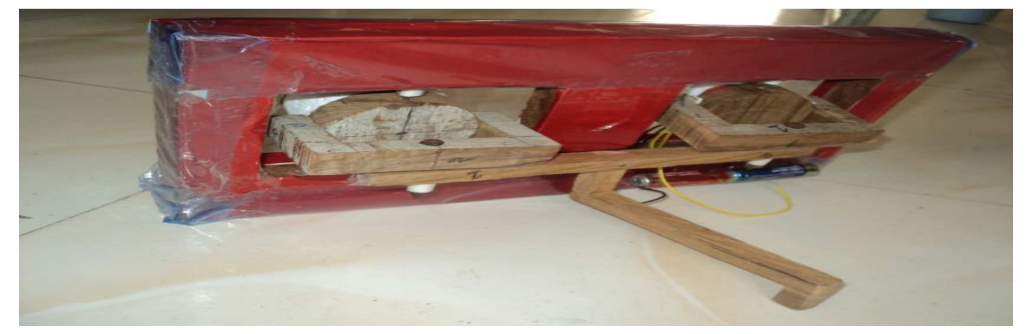

Figure 16: Fabricated Model (Rear View)

\section{RESULTS AND CONCLUSIONS}

In this project steering controlled headlights has been fabricated. Considering the car to be TATA Indica the dimensions have been calculated. These dimensions may differ from car to car based on the shape and size of the dome. The cross-sectional shape of the bars is considered to be circular but square or hollow pipe like structure may also be used. The ultimate goal of this system is transmitting linear motion of 'rack' of the steering mechanism to the rear end of the headlights where it changes into rotary motion of the headlights. Hence any changes in the shape of the links can be incorporated based on the requirements in the dome of a car. A very important factor that has been calculated is the 'Maximum angle of rotation' of the headlights on rotating the steering wheel whose result is $36^{0}$ away with respect to the line joining the C-clamp and the ball joint (axis holding the headlight in vertical plane). 


\section{Scope of the Project}

The developed model is based on the usage of movable C Clamp which can be replaced by rack and pinion mechanism through which the rotation of the headlight can be fixed as desired.

\section{REFERENCES}

1. J. P. Lowenau, J. H. Bernasch, H. G. Rieker, P. J. Th. Venhovens, J. P. Huber, W. Huhn-bmwag Research and Development, F. M. Riech-Technical university (Vienna)- "Adaptive Light Control (Alc)".

2. T. Hacibekir, S. Karaman, E. Kural, E. S. Ozturk, M. Demirci - "Adaptive Headlight System Using Hardware-In-The-Loop Simulation". Proceedings of the 2006 IEEE International Conference on control Applications Munich, Germany, October 4-6, 2006.

3. Alex. D. Hwang, EliPeli (Schepens Eye Research Institute, Department of Ophthalmology, Harvard Medical School, Boston, MA, USA, e-mail: eli.peli@schepens.harvard.edu)- "Headlight Glare Simulator For A Driving Simulator 2.0”Submitted to the

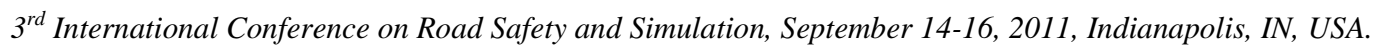

4. Kamble, N. and Saha, S. K. (200x) 'Developing a Virtual Prototype of a Rack and Pinion Steering System', Int. J. Vehicle System Modelling and Testing, Vol. $x$, No. $x$, pp. xxx-xxx.

5. Kobayashi, T. and Shibata, H. 'Estimation of Rack Swing Torque for Rack and Pinion Steering Gear' -JTEKT Engineering Journal English Edition No.1006E (2009).

6. Rajiv Dey - 'Electronic Power Assisted Steering System 'ISSN: 2277-3754 International Journal or Engineering and Innovative Technology (IJEIT) Volume 1, Issue 3, March 2012. 